\title{
A Conversation between Jackson Katz and Douglas Kellner on Guns, Masculinities, and School Shootings
}

\author{
Jackson Katz, Douglas Kellner
}

\begin{abstract}
Katz is the creator of the educational video Tough Guise: Violence, Media and the Crisis In Masculinity, and the author of The Macho Paradox: Why Some Men Hurt Women and How All Men Can Help. Douglas Kellner is George F. Kneller Chair in the Philosophy of Education at UCLA and author of the recently published Paradigm Press book Guys and Guns Amok: Terrorism and School Shootings from the Oklahoma City Bombings to the Virginia Tech Massacre..
\end{abstract}

JK: The one-year anniversary of the Virginia Tech massacre was April 16, followed by the ninth anniversary of Columbine just a few days later on April 20. As April 16 approached, there were all sorts of stories in the mainstream media about the tragedy. As someone who has written extensively about media culture but also now about gun violence, is there a way you can characterize media coverage of VT, NIU and other recent school shootings? In your opinion, what are some of the strengths and weaknesses of the coverage?

DK: For the most part, corporate media coverage of the school shootings remains on the level of media spectacle, presenting the events as tragedies, while failing to go into the features that the shootings have in common. One searches in vain in the corporate media for discussion of a "crisis in masculinity" or a thoughtful critique of our out-of-control gun culture, and yet in most of the tragedies, the shooters use guns and violence to resolve their masculine identity crises and create celebrity for themselves through acts of violence.

JK: In your book Guys and Guns Amok, you link incidents of domestic terrorism like the 1995 Oklahoma City bombing to the phenomenon of school shootings. Can you explain the similarities (and differences) as you see them?

DK: In both school shootings and acts of domestic terrorism the perpetrators use guns and/or commit violence to resolve crises in masculinity and to constitute themselves as "tough guys," real men. They also use the media to create media spectacles of terror and to constitute themselves as celebrities, hence the title of my book, "Guys and Guns Amok."

JK: Can you describe the origins of the word "amok," as well as your use of the term in relation to school shootings and other killing rampages?

DK: The initial title "Guns Amok" emerged as I was outlining a table of contents for this book. As it turns out, there were many Google references that connected "guns" and "amok"; there were almost thirty films with "Amok" in their title, including a Chuck Jones Daffy Duck film "Duck Amuck" that I recalled when thinking about the title, as well as a Star Trek episode "Amok Time," that I remember well. There are books and journals with "Amok" in their title, including Stefan Zweig's novel Amok (1922). Hence, there are enough cultural references to make the title resonant and viable. 
To be sure, the problem with the Virginia Tech and other school shootings is not guns running amok, but people with guns killing other people. Thus the editorial board at Paradigm Press suggested the current title Guys and Guns Amok. This seemed appropriate as I wanted to argue that both an out-of-control gun culture and problematic constructions of masculinity were behind the killing and violence that I am engaging in this book. Moreover, the word "amok" has anthropological grounding with various accounts of lonely, frustrated and disturbed men who have suffered loss going beserk, running amok (a Malay word) and randomly killing people (see Steven Pinker How The Mind Works, 1997). Since "running amok" takes place in specific societal contexts, in my book I situate my analyses within the context of violence and guys and guns amok in contemporary U.S. society and culture.

JK: Many school shooters kill themselves, or enact a plan where they are almost certain to be killed by police. In that sense, are there any notable similarities between the motivations of American school shooters and Islamist suicide bombers from the Middle East? Notable differences between them?

DK: Domestic terrorists, like Timothy McVeigh who perpetrated the Oklahoma City bombings, are often prepared to sacrifice their lives for political purposes, as are Middle Eastern terrorists. Likewise, it appears that many school shooters are so full of rage that they are prepared to die to become martyrs to avenge their grievances and as a way of gaining immortality as celebrities.

JK: Your book's title foregrounds the issue of gender in the discussion of violence. Yet the mainstream media discourse about school shootings is typically degendered, with reporters and commentators referring to "perpetrators," "shooters," "individuals," "kids killing kids," etc., when nearly all of the killings are done by men and boys. You employ the concept of a "crisis in masculinity" that I have also used in my work. What is your understanding of this crisis in masculinity, and how do you see this crisis playing a role in these killings?

DK: By a "crisis in masculinity," I mean a dominant societal connection between masculinity and being a tough guy, assuming what you have described in your own work as a "tough guise," a mask or façade of violent assertiveness, covering over vulnerabilities. The crisis erupts in outbreaks of violence and societal murder, as men act out rage, which takes extremely violent forms such as political assassinations, serial and mass murders, and school and workplace shootings - - all exhibiting guys and guns amok. The crisis in masculinity is grounded in deteriorating socio-economic possibilities for men and is aggravated by our current economic crisis. It is also produced in part by a media which shows violence as a way of solving problems and is also connected to the escalation of war and militarism in the United States from the long nightmare of Vietnam through the military interventions of the BushCheney administration in Afghanistan and Iraq, as well as escalating societal violence in the media and society at large.

JK: How do factors of class and race enter into the problem of school shootings?

DK: A multicausal analysis needs to look at multiple factors of class, race, gender, and specific social environments in which shootings take place. So far, research suggests that black and Latino shootings tend to be specific-target incidents that are related to particular issues or personal conflicts. The striking thing about many of the shootings from Columbine to the present was that it was white middle-class school shooters who tended to attack their victims indiscriminately, showing that alienation and violence is expanding through all classes, races, and sectors of contemporary U.S. society.

JK: You write about media spectacle and the ways that the media construct our views of contemporary events and history. You also lay out various types of spectacles: spectacles of terror, spectacles of horror, political spectacles, megaspectacles. Can you provide an overview of your idea of spectacle?

DK: My notion of media spectacle builds on French theorist Guy Debord's conception of the society of spectacle, but differs significantly from Debord's concept. For Debord, spectacle "unifies and explains a great diversity of apparent phenomena" (Debord 1967:10). Debord's conception, first developed in the 1960s, continues to circulate through the Internet and other academic and subcultural sites today. It describes a media and consumer society, organized around the production and consumption of images, commodities, and staged events. 
For Debord, "spectacle" constituted the overarching concept to describe the media and consumer society, including the packaging, promotion, and display of commodities and the production and effects of all media. Using the term "media spectacle," I am largely focusing on various forms of technologically-constructed media productions that are produced and disseminated through the so-called mass media, ranging from radio and television to the Internet and the latest wireless gadgets. Every medium, from music to film and television, from news and information to advertising, has multiple forms of spectacle, involving such things in the realm of news as spectacles of terror related to terrorist episodes or school shootings, spectacles of horror such as hurricanes and other natural events, or the collapse of mines or horrific auto accidents, as well as political and celebrity scandals, all attesting to the trend toward tabloid journalism and "infotainment." The forms and circulation of the spectacle evolve over time and multiply with new technological developments.

Megaspectacles constitute a situation whereby certain spectacles become defining events of their era. They include socio-political dramas that characterize a certain period, involving such things as the 1991 Gulf war, the O.J. Simpson trials, the Clinton sex and impeachment scandals, or the Terror War that has defined the era from 9/11 to the present, and, currently, the 2008 presidential election. Megaspectacles are defined both quantitatively and qualitatively. The major media spectacles of the era dominate news, journalism, and Internet buzz and are highlighted and framed as the key events of the age, as were, for instance, the Princess Diana wedding, death, and funeral, the extremely close 2000 election and 36 Day Battle for the White House, or the September 11 terror attacks and their violent aftermath. Since the 1990 s, there have been recurrent spectacles of terror such as terrorist attacks, or school shootings which I see as a form of domestic terrorism.

JK: In the Northern Illinois University shooting, the killer walked into a crowded lecture hall and started shooting. He was therefore making an unambiguously public statement. Like Cho at Virginia Tech, who actually produced a video he released to the media just before enacting his crime, was the NIU shooter in a sense the writer, director and producer of his own media spectacle? If so, does this feature of his rampage teach us anything about the media culture in which we are immersed? Given the profit-centered motivations of TV networks and others in the media industries, centrally among them demands and pressures for higher ratings, do you have any thoughts about how media organizations can responsibly cover school shootings?

DK: Cho's multimedia video dossier, released after the Virginia Tech shootings, showed that he was consciously creating a spectacle of terror to create a hypermasculine identity for himself and avenge himself to solve his personal crises and problems. The NIU shooter, dressed in black emerged from a curtain onto a stage and started shooting, obviously creating a spectacle of terror, although as of this moment we still do not know much about his motivations. As for the television networks, since they are profit centers in a highly competitive business, they will continue to circulate school shootings and other acts of domestic terrorism as "breaking events" and will constitute the murderers as celebrities. Some media have begun to not publicize the name of teen suicides, to attempt to deter copy-cat effects, and the media should definitely be concerned about creating celebrities out of school shooters and not sensationalize them.

JK: You say that you see media spectacle as a contested terrain, that citizens/audiences are not merely passive objects that media dictates to. What are some of the ways that people can resist playing the role of passive media consumer as the spectacle of these school shootings plays out?

DK: People have to become critical of the media scripts of hyperviolence and hypermasculinity that are projected as role models for men in the media, or that help to legitimate violence as a means to resolve personal crises or solve problems. We need critical media literacy to analyze how the media construct models of masculinities and femininities, good and evil, and become critical readers of the media who ourselves seek alternative models of identity and behavior.

JK: The NIU murders come on the heels of several recent rampage killings, and of course the Virginia Tech massacre last April. You report that the Virginia Tech massacre was the twenty-fifth school shooting on an American campus since Columbine in 1999. That figure represents more than half the number of of school shootings across the world in the same time span. You argue for a multicausal explanation of the phenomenon of school shootings. 
What do you see as some of the key reasons why there are so many school shootings in this country? Is it facile to say, as some have argued, that the crux of the problem is a function of the easy availability of firearms? Is that too simplistic an explanation? What are some of the other cultural factors that are implicated?

DK: First of all, I want to make it clear that there is not one defining cause of the school shootings that are escalating. To be sure, they are in part a product of guys and guns amok and the escalation of gun ownership, the crisis in masculinity, the rise in societal and global violence, and a media which portrays violence as a solution to personal, political and social problems, and which create media spectacles that make celebrities out of school shooters and terrorists. Yet, we also need to address youth alienation, crises in schooling and families, and escalating societal violence. Since there are multiple factors involved in the specific shootings and acts of domestic terrorism, we need a multiple range of solutions.

JK: You lecture frequently around the world. What are some of the things you've heard from people in other countries about killing rampages in the U.S.? Does discussion typically focus on the lax gun laws here? In the course of your travels and interactions with colleagues and others overseas, have you heard any insightful comments about U.S. culture from an external vantage point that have allowed you to see domestic reality through a new lens?

DK: School shooting is becoming a global problem so there is concern with it everywhere. In fact, it appears that the U.S. has in a sense been exporting school shootings as they have begun to appear more frequently in countries throughout the world. Yet, many people in other countries are astonished that we have such lax gun laws and that one can buy assault rifles and handguns and ammunition over the Internet, or from gun shows where there is not even a background check. Other countries have passed more restrictive gun laws after dramatic school shootings, just as countries produce stricter security measures after terrorist attacks.

JK: College administrators as well as faculty and staff are on high alert; everyone is aware that these tragedies could happen on their campus. What can be done to prevent further incidents? You have written that there are several important developments that have been catalyzed by the Virginia Tech tragedy, including: 1) More intense and comprehensive focus on school security; 2) More intense focus and scrutiny of mental health issues; 3) Renewed debate about gun control and the role of guns in U.S. society; and 4) A renewed focus on the need to reconstruct education in a way that emphasizes the need to teach peace studies, non-violent conflict resolution, critical media literacy, and citizenship. Can you speak to these positive outcomes, as well as their limitations?

DK: Most schools, colleges and universities now have plans in place to provide better mental health protocols and facilities to deal with students with problems. There is also growing concern with campus security and quick responses in terms of information and campus security when shooting or terror episodes occur. Obviously, though, we need further debate about gun laws, male violence and rage, and thus seeing guys and guns amok as a serious problem. Likewise, we need to address problems of increasing societal violence, youth alienation, dysfunctional schools and families, and many other issues.

JK: After the NIU shooting, as with Virginia Tech, the mainstream media seized upon the idea of "mental illness" as the explanatory framework when it came to ascertaining a motive for the killings. But the vast majority of mentally ill are not violent. Also, there are large numbers of women who suffer from various forms of mental illness. If so, why are female school shooters so rare? Is there something about masculinity and mental health in the contemporary era that these shootings might be telling us?

DK: The term "mental illness" is a social construct and tells us that someone has a serious problem and that we need to have better institutions and people to help us deal with this problem. Obviously, men are suffering particular forms of mental health problems and crises in masculinity and so of course we need to deal with cultural constructs of masculinity and femininity in terms of how we define and deal with mental health or illness.

JK: After the NIU shootings, right-wing talk radio caller lines lit up with calls for issuing conceal carry permits to students and professors -- in essence to respond to violence with violence -- or the threat of it. Can you talk about 
the way the politics of guns and the NRA helps shape media coverage and national discourse about mass killings done with firearms?

DK: As a Professor and lecturer, I can say that the last thing in the world I want is guns in classrooms, or lecture halls. This is just asking for an increase of violence. The fact that in many states there are laws being debated about letting students and teachers carry concealed weapons on campus testifies to the power of the NRA and right-wing gun groups. Rather, we need serious discussions of what causes school shootings and how to deal with potential problems, rather than unleashing an army of would-be Rambos and vigilantes.

I should note that as a philosopher of education and critical theorist of society I do not want to reduce the analysis to more school surveillance and security, or more mental health screening and psychological services, but rather to try to put the problem in a broader context of societal violence, the alienation of youth, and the need to reconstruct education and society to have healthier images of masculinity, and to reconstruct education to bring in more peace and human rights education, multiculturalism and the respect for difference, including women's and men's studies, ethnic studies, environmental studies, and the philosophy of education generally.

JK: You write that new media and new technologies play a part in rapidly circulating extremist ideologies and provide ready examples of redemptive violence, which is a major theme of contemporary Hollywood film. Talk radio and Internet sites and discussion groups also provide outlets for white male rage. Elsewhere, you have written about the potential of new media technologies to catalyze and create community and connection. What are some other ways that new media either contribute to the contemporary phenomenon of mass killings, or can be employed to prevent them?

DK: Obviously, the Internet has a lot of pro-gun sites that present guns as necessary tokens of hypermasculinity and allow people to buy weapons and ammunition. This definitely needs to be dealt with as a societal problem. On the other hand, the Internet can be a great source of information and enlightenment that criticizes extreme violence from the Iraq war to Al Qaeda terrorism and that promotes peace, understanding, and non-violent conflict resolution—-themes that also need to be taken up in our schools, colleges and universities.

JK: Is there some way that college communities can respond to these shootings that goes beyond upgrading law enforcement policies and procedures? I am thinking specifically about the role of faculty in offering forums for constructive intellectual inquiry into this problem, which people tend to see - understandably -- as a law enforcement and public safety matter first and foremost. For example, when you wrote Guys and Guns Amok, how were you envisioning it would be used? Who is your target audience? What role can a cultural studies analysis play in the prevention of future tragedies?

DK: Schools from K-12 plus institutions of higher education need to take the issue of school shootings very, very seriously and examine the cases sociologically, to discuss causes, and to seek solutions. I envisaged Guys and Guns Amok as providing an overview of the problem, as well as an examination of some related issues, debates, and possible solutions. I would like also to promote critical media literacy courses to make students and citizens critical readers of the media, to learn to create alternative information and media, and to be more socially and politically aware. This involves what John Dewey called citizenship training and making us all more responsible citizens, able to deal with ongoing social problems. It also involves dealing with crises in masculinity and providing new images of masculinity and femininity, and a reconstruction of education that makes it more relevant to the crises of the contemporary era.

\section{THE END}


